\title{
Effect of Ribose on Mature/Immature Raw Peanut Proteins and Their Allergenic Properties
}

\author{
—Maillard Rx of Ribose with Mature/Immature Peanut Proteins and Their IgE Binding
}

\section{Si-Yin Chung}

United States Department of Agriculture, Agricultural Research Service, Southern Regional Research Center, New Orleans, USA. Email: siyin.chung@ars.usda.gov

Received January $3^{\text {rd }}, 2011$; revised February $18^{\text {th }}, 2011$; accepted March $21^{\text {st }}, 2011$.

\begin{abstract}
Mature and immature roasted peanuts are reportedly different in the level of Maillard reaction adducts (MRA) and IgE binding (i.e., allergenic capacity). Heating and sugar-protein interaction are the cause for the difference. The objective of this study was to determine if mature and immature raw peanuts (not roasted) are also different through treatment with a reducing sugar such as ribose, glucose or fructose at a mild temperature. Extracts from mature and immature raw peanuts were treated with individual sugars at $37^{\circ} \mathrm{C}$ and $50^{\circ} \mathrm{C}$, respectively, for $0-10$ days, and then assayed for $M R A$ with nitroblue tetrazolium (NBT) in a time-course manner for 60 min. IgE binding was determined in an enzymelinked immunosorbent assay (ELISA), using a pooled plasma from peanut-allergic individuals. Of the sugars tested, only ribose produced a big difference or a unique curve pattern in MRA between treated mature and immature peanuts. The unique curve pattern was more pronounced at $50^{\circ} \mathrm{C}$ (day $\left.5-10\right)$ than at $37^{\circ} \mathrm{C}$. IgE binding under this condition increased, but only with the ribose-treated mature raw peanut. It was concluded that mature and immature raw peanuts were different in MRA and IgE binding when treated with ribose only, and that under such a condition, mature and immature raw peanuts could be identified.
\end{abstract}

Keywords: Maillard Reaction, Ribose, Peanut Maturity and Allergenic Properties, Nitroblue Tetrazolium, IgE

\section{Introduction}

Ribose, a functional five-carbon sugar and an emerging nutraceutical ingredient [1], is known for its high reactivity with proteins via the Maillard reaction (a sugar-protein reaction) [2]. In the Maillard reaction, the $\varepsilon$-amino groups of the protein react with the carbonyl groups of reducing sugars to form Amadori products which further transform to browning, advanced glycation end products. In this case, ribose reportedly reacts with proteins much faster than other common sugars (e.g., glucose, fructose, galactose, rhamnose, lactose and arabinose), and results in glycated proteins with a higher radical scavenging and antioxidant activity $[3,4]$. Because of its high reactivity, ribose has been used to modify the texture of noodles [5] and tofu [6].

Products formed and bound to the proteins in the Maillard reaction can be detected using nitroblue tetrazolium (NBT). In the assay, the products (ketoamines) reduce NBT and produce a colored formazan dye with an absorption maximum at $530 \mathrm{~nm}$ [4]. Using this assay,
Maillard reaction adducts (MRA) have been found in immature and mature roasted peanuts [7]. The latter not only reportedly has more MRA but also a higher immunoglobulin $\mathrm{E}$ (IgE) binding (i.e., allergenic capacity) than the immature roasted peanut. However, in the raw state, mature and immature peanuts are not different in MRA or IgE binding (unpublished data). This study postulated that mature and immature raw peanuts may be different or differentiated if their extracts are subjected to heating with a reducing sugar at mild temperatures (e.g., 37 $50^{\circ} \mathrm{C}$ ). The maturity of peanuts is important because immature raw peanuts tend to develop fruity fermented offflavors during roasting [8]. To date, the commonly known methods for identifying mature and immature raw peanuts are the size-screening [9] and hull-scraped pod color methods [10].

The objective of this study was to determine if extracts from mature and immature raw peanuts are different in MRA and IgE binding when treated with a reducing sugar such as ribose under mild temperatures. Ribose was chosen because it is reportedly the most reactive 
reducing sugar in the Maillard reaction [4]. Other reducing sugars such as glucose and fructose were also examined to compare with ribose. IgE binding was determined because it has been shown to be related to MRA [11-14] and peanut maturity $[7,11]$. If confirmed, the current research (using ribose) may have a potential application in the prediction of peanut maturity and allergenic property prior to roasting, and could be an alternative method to the size-screening and hull-scraped pod color methods described above.

\section{Materials and Methods}

\subsection{Materials}

Goat anti-human IgE-peroxidase conjugate, Tris buffered saline tablets (TBS), o-phenylenediamine, and Tween 20 were purchased from Sigma Co. (St. Louis, Mo, U.S.A.). Human plasmas from three individuals with peanut allergy (determined by CAP-FEIA assay for $\operatorname{IgE}$ ) were obtained from PlasmaLab International (Everett, Wa, U.S.A.). Raw high-oleic and Florunner peanuts (mature and immature) were from the University of Florida, Gainesville, FL, U.S.A. and National Peanut Research Laboratory, Dawson, GA, U.S.A., respectively. Superblock blocking buffer and bicinchoninic acid (BCA) kit were purchased from Pierce Chemical Co. (Rockford, Il, U.S.A.).

\subsection{Determination of Peanut Maturity}

Maturity was determined by kernel size. In this case, Jumbo and \#1 refer to mature and immature raw peanuts. Although kernel size is not an objective measure of maturity, the percentage of mature kernels in a sample generally increases with increasing size [9]. Also, maturity was determined by a visual hull-scrape color method [10] in which peanuts were sorted by pod color exposed after hull scraping. In this case, "Yellow" and "Black" refer to immature and mature raw peanuts.

\subsection{Preparation of Extracts from Mature/Immature Peanuts (Black/Yellow; Jumbo/ \#1)}

Normal raw peanuts (Forunner) and new breeds (higholeic peanuts) were used for this purpose. Prior to extraction, peanuts were sorted, based on color, for Black (mature) and Yellow (immature), and also, based on seed size, for Jumbo (mature) and \#1 (immature). They were further processed into defatted peanut meals [7] by grinding the mature and immature raw seeds with a Wiley mill in acetone and then in hexane (both in dry ice), followed by air drying. Extracts were then prepared by stirring the defatted meals $(400 \mathrm{mg})$ in $3 \mathrm{~mL}$ of $0.02 \mathrm{M}$ sodium phosphate, $\mathrm{pH} 8.0$, for $30 \mathrm{~min}$ at $25^{\circ} \mathrm{C}$, followed by centrifugation at $8500 \mathrm{~g}$ for $10 \mathrm{~min}$. Concentration of proteins in the extract was determined using the BCA assay.

\subsection{Treatment of Mature/Immature Peanut Extracts with Reducing Sugars}

Treatment was performed with a slight modification of the method of Chobert et al. [4]. Briefly, extracts were each diluted to a concentration of $5 \mathrm{mg} / \mathrm{mL}$ and incubated ( $250 \mu \mathrm{L}$ each) with $250 \mu \mathrm{L}$ of $0.3 \mathrm{M}$ sugar (ribose, glucose or fructose) in $0.3 \mathrm{M}$ sodium phosphate buffer, $\mathrm{pH} 8$, containing $0.01 \%$ sodium azide, respectively at $37^{\circ} \mathrm{C}$ and $50^{\circ} \mathrm{C}$ for $0,2,5$ and 10 days. Two different temperatures were performed so a difference in the reaction rate could be compared. A temperature of higher than $50^{\circ} \mathrm{C}$ was not carried out because proteins tended to aggregate under that condition.

\subsection{NBT Assay of Sugar-Treated Mature/Immature Extracts (Black/Yellow; Jumbo/ \#1)}

After sugar treatment, extracts $(5 \mu \mathrm{L})$ were each mixed in duplicate with a $200 \mu \mathrm{L}$ of $250 \mu \mathrm{M}$ nitroblue tetrazolium

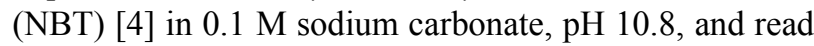
continuously at 5 -min interval, $570 \mathrm{~nm}$ and $37^{\circ} \mathrm{C}$ for $60 \mathrm{~min}$, using a microtiter plate reader (CERES 900C model, Bio-Tek Instruments, Inc., Winooski, Vt, U.S.A.). Time-course curves $(0-60 \mathrm{~min})$ representing Yellow (immature) and Black (mature) were plotted. Similar curves were plotted for \#1 (immature) and Jumbo (mature) in separate Figures. All values are mean of two determinations. Statistical analyses were carried out to determine the difference in mean between the pairs (Yellow and Black; and \#1 and Jumbo), using a Student's $t$-test ( $p$ $<0.05)$.

\subsection{Determination of IgE Binding to Sugar-Treated Peanut Extracts}

IgE bindings were determined in an indirect ELISA according to the method of Chung et al. [7]. Briefly, a microtiter plate was incubated with sugar-treated peanut extracts $\left(20 \mu \mathrm{g} / \mathrm{mL}, 100 \mu \mathrm{L}\right.$ per well) at $37^{\circ} \mathrm{C}$ for $2 \mathrm{hrs}$. After incubation and washing with TBS/Tween 20 $(0.05 \%)$, the plate was blocked with a Superblock buffer solution $(200 \mu \mathrm{L}$ per well) overnight at room temperature. After blocking and wash, a diluted pooled plasma containing IgE antibodies $(1: 30)(100 \mu \mathrm{L})$ from peanut-allergic individuals was added to the plate and incubated for $30 \mathrm{~min}$ at room temperature. The plate was again washed, followed by addition and incubation of a goat anti-human IgE peroxidase conjugate $(1: 500)$ for $30 \mathrm{~min}$ at room temperature. After incubation and wash, a substrate of $o$ phenylenediamine $(0.5 \mathrm{mg} / \mathrm{mL})$, containing $0.03 \%$ hy- 
drogen peroxide in $0.1 \mathrm{M}$ citrate buffer, $\mathrm{pH} 5.5$ was added. After $10 \mathrm{~min}$, the color reaction was stopped by adding $4 \mathrm{~N} \mathrm{H}_{2} \mathrm{SO}_{4}(50 \mu \mathrm{L})$. The absorbance was read at 490 $\mathrm{nm}$. All values are mean of triplicate. Statistical analyses were performed to determine the difference in mean between Yellow and Black and between \#1 and Jumbo, using a Student's $t$-test $(p<0.05)$.

\section{Results and Discussions}

\subsection{Ribose-Treated Mature/Immature Raw Peanut Extracts in NBT Assay}

Normal peanuts (Florunner). Figure 1 shows the timecourse NBT reaction curves of mature and immature raw peanuts (Jumbo and \#1) treated with ribose at $37^{\circ} \mathrm{C}$ and $50^{\circ} \mathrm{C}$, respectively, for $0,2,5$ and 10 days. On day 0 , no curves were observed, indicating that there were no or undetectable Maillard reaction adducts in the untreated peanut extracts. On day 2 at $37^{\circ} \mathrm{C}$, adducts were detected, but the time-course curves for mature and immature peanuts did not show a difference or separation from each other. As the ribose treatment continued at $37^{\circ} \mathrm{C}$ for 5 - 10 days, the curves began to separate at $30-50 \mathrm{~min}$ and form a "gap" region between them. This phenomenon also happened to the samples at $50^{\circ} \mathrm{C}$. However, at $50^{\circ} \mathrm{C}$, the "gap" was larger and more pronounced on days 5 and 10 , as compared to $37^{\circ} \mathrm{C}$. Further treatment at a longer time ( $>10$ days) did not yield a much larger "gap" region (data not shown). This indicates that the optimal treatment time for the "gap" region to occur was 10 days.

The "gap" region described above is indicative of a difference in level of Maillard reaction adducts and a unique feature between immature and mature raw peanuts. In this case, mature peanuts exhibited a higher level of Maillard reaction adducts than the immature. The mechanism for this difference is not clear, but probably is because mature peanuts contain more of the following amino acid residues which reacted with ribose: lysine, tyrosine, phenylalanine [15]. These amino acids have been reported to be the most reactive in Maillard reaction among the three groups of amino acids proposed by Ashoor and Zent [16], where Group 1 contains the above described amino acids; Group 2 includes alanine, valine, leucine, methionine, proline, asparagine and glutamine, followed by the less reactive Group 3 which includes histidine, arginine, aspartic acid, and glutamic acids.

To further support the above data, Yellow (Ye) and Black (Bl) which were classified as immature and mature raw peanuts, based on the hull-scrape color method [10], were examined. Extracts of $\mathrm{Ye} \& \mathrm{Bl}$ were treated with ribose at $37^{\circ} \mathrm{C}$ and $50^{\circ} \mathrm{C}$, respectively, for 10 days and then assayed with NBT. Day 10 was chosen because as described above, it was the time when the size of the "gap" region between immature and mature ribose- treated peanuts reached the maximum. Figure 2(a) shows the time-course NBT reaction curves of ribose-treated $\mathrm{Ye}$ and $\mathrm{Bl}$ at $37^{\circ} \mathrm{C}$ and $50^{\circ} \mathrm{C}$, respectively. In both cases $\left(37^{\circ} \mathrm{C}\right.$ and $\left.50^{\circ} \mathrm{C}\right)$, a gap region was seen, where $\mathrm{Bl}$ was always represented by the top curve and Ye represented by the bottom curve. Also, the "gap" was larger at $50^{\circ} \mathrm{C}$ than at $37^{\circ} \mathrm{C}$. This finding agreed with the data $\# 1$ and Jumbo) presented in Figure 1, and indicates that the "gap" region could be a potential indicator of the difference between mature and immature raw peanuts.

New breeds (high-oleic peanuts). High-oleic peanut is a new peanut breed that has a higher content of oleic acid and a longer shelf-life than regular peanut [17]. The purpose of this experiment was to determine if a new breed behaves the same or differently from the regular peanut in the ribose treatment and NBT assay. In this case, Yellow (Ye) and Black (Bl) representing immature and mature raw high-oleic peanuts were used to compare with the normal peanuts (Florunner) (Figure 2). Day 10 was chosen as described above. Figure 2(b) shows the timecourse curves of NBT reacting with Ye and Bl high-oleic extracts treated at $37^{\circ} \mathrm{C}$ and $50^{\circ} \mathrm{C}$, respectively, with ribose on day 10. Again, a "gap" region or difference in levels of Maillard reaction adducts between Ye and $\mathrm{Bl}$ was seen. The data suggests that new peanut breed (higholeic) is not different from normal peanut (Florunner) in the ribose reaction and NBT assay.

\subsection{Glucose- and Fructose-Treated Mature/Immature Raw Peanut Extracts in NBT Assay}

Glucose and fructose are known to be less reactive with proteins than ribose in terms of forming Maillard reaction adducts $[3,4]$. Whether these sugars, after reacting with peanut proteins, behave like ribose (i.e., forming a "gap" region) in the NBT assay is not known. The objective was to determine if the "gap" region forms in the NBT assay of glucose- and fructose-treated mature and immature raw peanut extracts. Figure 3 shows the typical time-course reaction curves of mature and immature raw peanuts (Jumbo and \#1) treated with glucose and fructose, respectively, at $37^{\circ} \mathrm{C}$ and $50^{\circ} \mathrm{C}$ for 10 days. In all cases, both glucose and fructose treatments did not result in the formation of a "gap" region between \#1 and Jumbo in the NBT assay. Further treatment with the sugars for a longer time (i.e., 20 days) yielded the same result (i.e., no gap), and similar patterns were also seen with $\mathrm{Bl}$ and $\mathrm{Ye}$ (data not shown). This finding indicates that glucose and fructose are different from ribose in their reactions with peanut proteins, and that mature and immature raw peanuts could not be differentiated in the NBT assay, using the glucose or fructose treatment. 

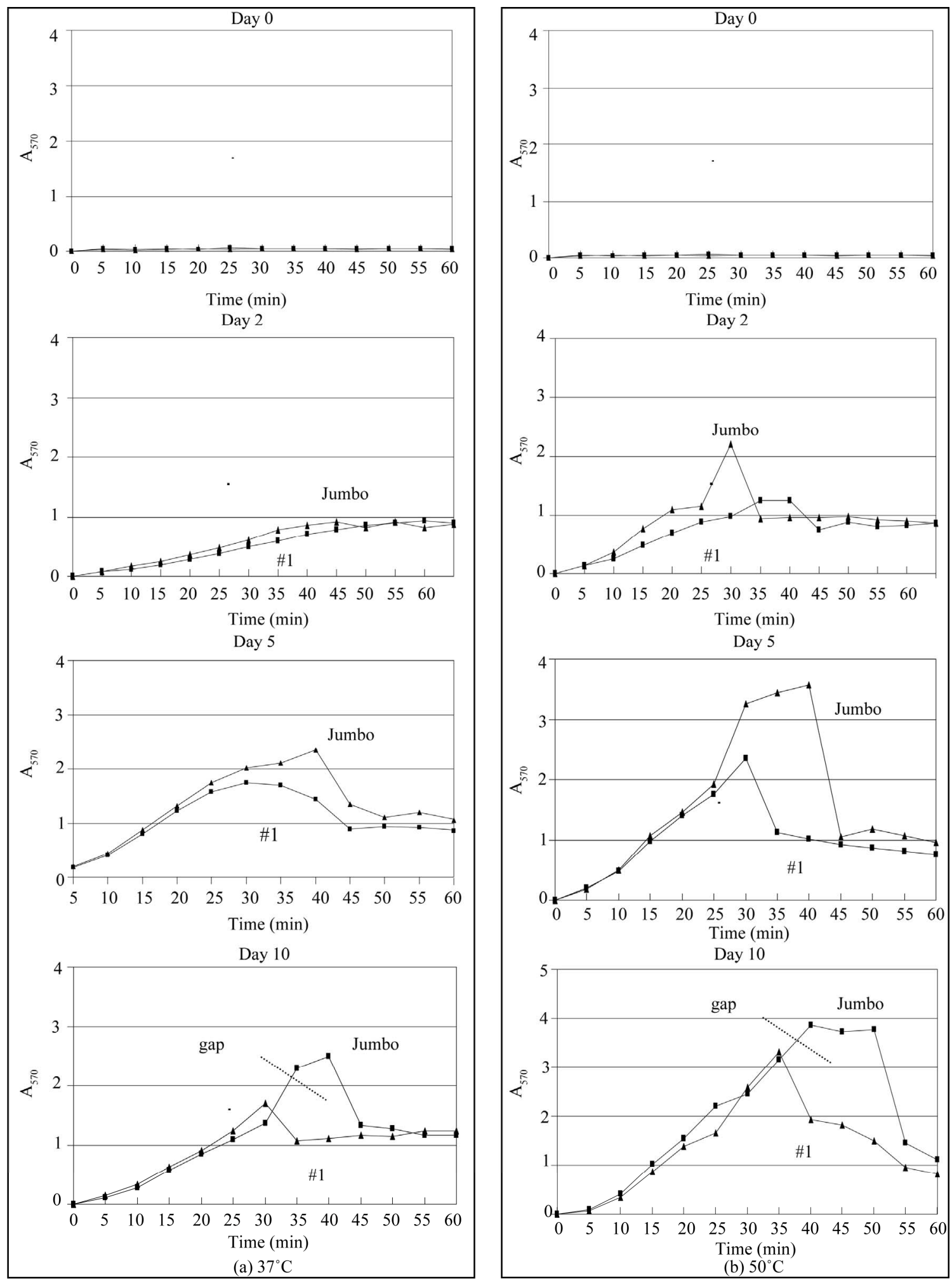

Figure 1. Time-course reaction of NBT with ribose-treated extracts from mature (Jumbo) and immature (\#1) raw peanuts (Florunner). Maturity was determined based on size. Raw peanut extracts were treated with ribose at $37^{\circ} \mathrm{C} \mathrm{(a)} \mathrm{and} 50^{\circ} \mathrm{C}(\mathrm{b})$, respectively, for the time indicated $(0,2,5,10$ days), and then incubated with NBT and read continuously at $570 \mathrm{~nm}$ in a microplate reader for $60 \mathrm{~min}$. Values are mean of duplicate. Values of Jumbo and \#1 in the "gap" region are significantly different from each other $(p<0.05)$. 

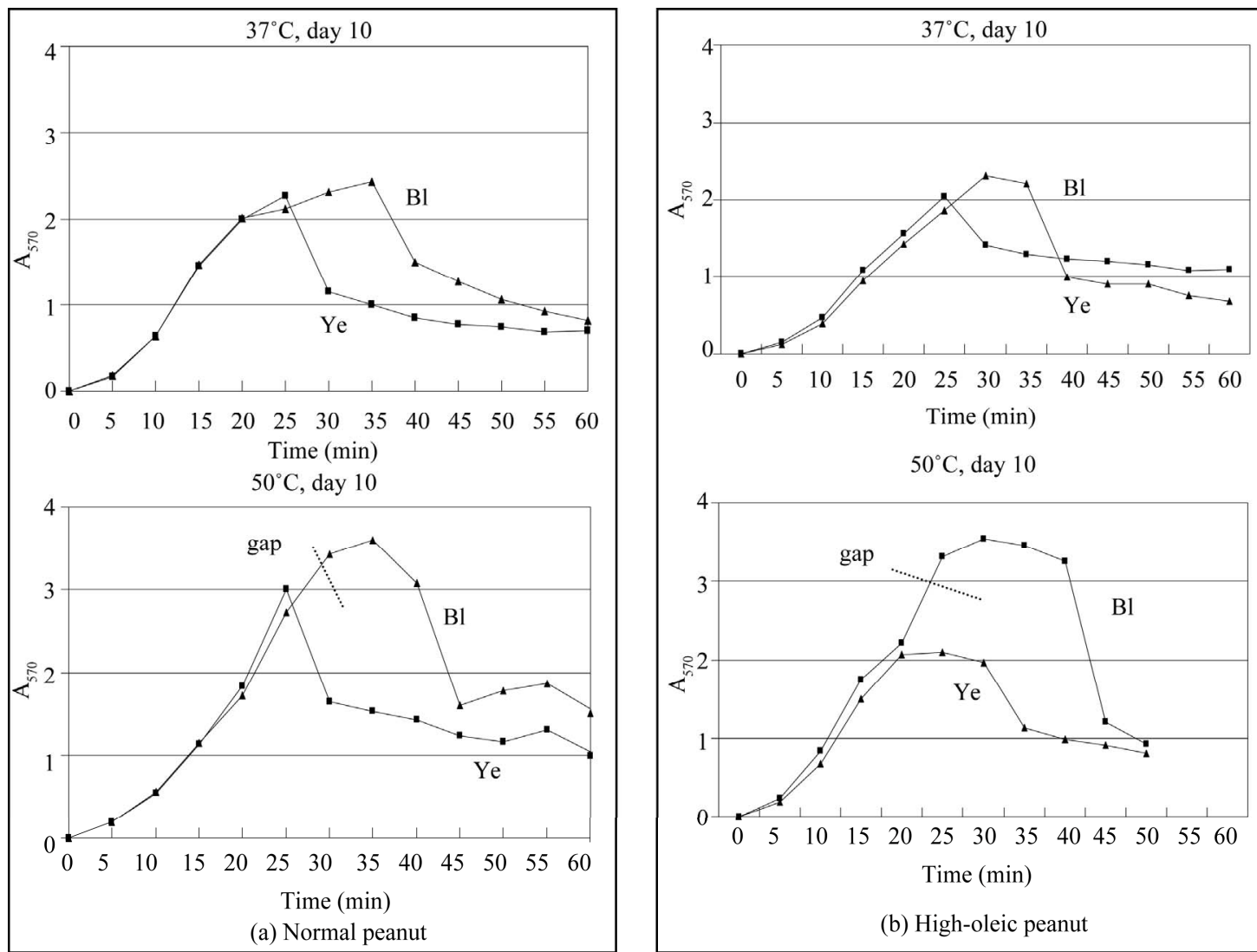

(b) High-oleic peanut

Figure 2. Time course reaction of NBT with ribose-treated extracts from (a) normal peanut (Florunner) and (b) high-oleic peanut (new breed) of different maturity. Ye = immature; $\mathrm{Bl}=$ mature (maturity determined based on hull-scrape color). Raw peanut extracts were treated with ribose and analyzed as described in Figure 1.
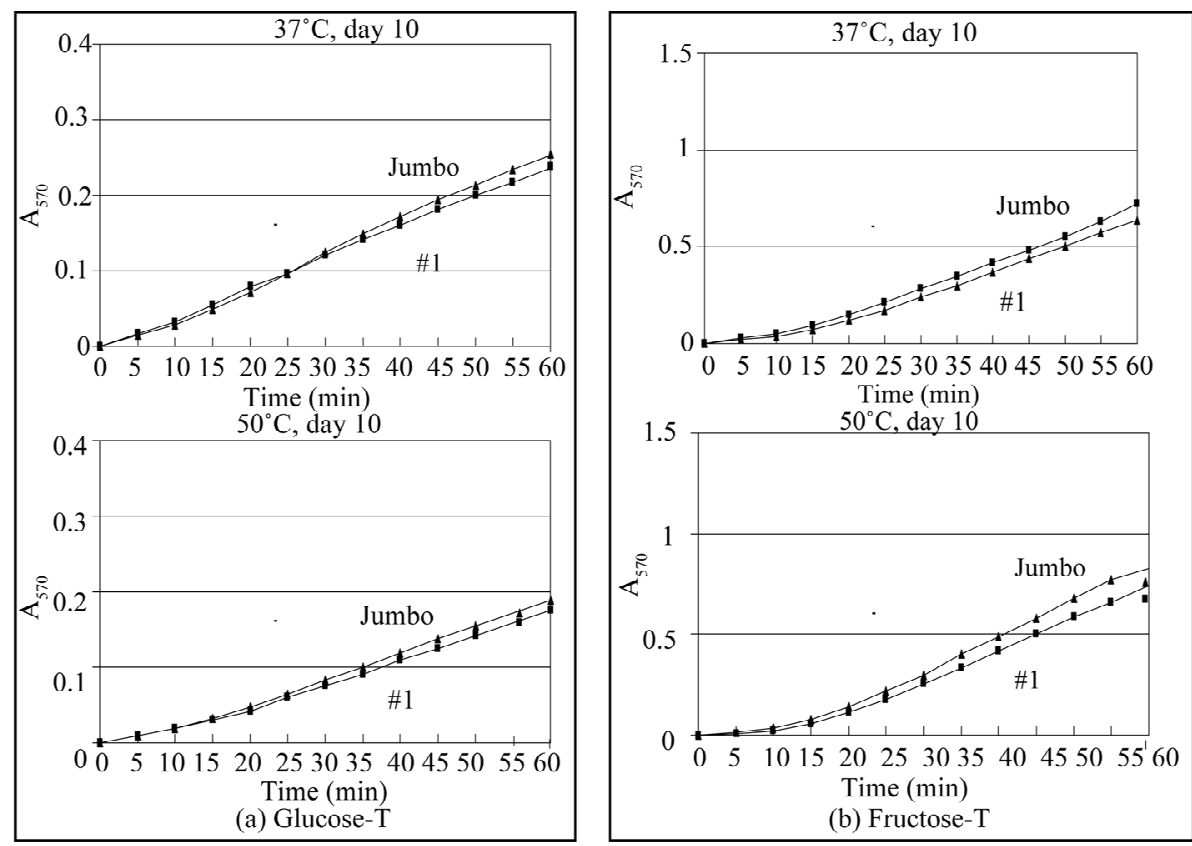

Figure 3. Time-course reaction of NBT with glucose-treated (a) and fructose-treated (b) peanut extracts of different maturity. Jumbo = mature; \#1 = immature. Treatment and NBT assays were carried out in the same way as described in Figure 2, except that ribose was replaced by glucose and fructose. $T=$ treated. 


\subsection{IgE Binding of Ribose-Treated Peanut Extracts in ELISA}

Effects of sugar-protein or Maillard reaction on the allergenic property or IgE binding to allergens from shrimp [18], milk [19], buckwheat [20] and peanuts [11-13] have been studied. In the latter three studies (peanuts), increased IgE binding has been reported. Also, glycation of a food allergen by the Maillard reaction has been shown to enhance its T-cell immunogenicity [14]. All this suggests that Maillard reaction could be capable of enhancing the allergenicity of food allergens in allergic subjects. To determine if Maillard reaction in this study has an effect on $\operatorname{IgE}$ binding of peanut proteins, sugar-treated peanut extracts were examined in an indirect ELISA. Figure 4 illustrates a typical profile of $\operatorname{IgE}$ binding of mature and immature peanuts (Jumbo and \#1) treated with ribose at $50^{\circ} \mathrm{C}$ for $0-10$ days. On day $0-2$, there was no difference in $\operatorname{IgE}$ binding between Jumbo and \#1. It was not until days 5 and 10 that a significant increase $(p<0.05)$ in IgE binding of Jumbo was observed, but $\mathrm{IgE}$ binding of $\# 1$ remained unchanged during that period. At $37^{\circ} \mathrm{C}$, Jumbo and $\# 1$ were not different in IgE binding, and this also occurred to extracts treated with glucose and fructose at both temperatures (data not shown).

Based on the above findings, Maillard reaction appears to be associated with IgE binding only when the following conditions are met: 1) temperature; 2) length of treatment time; 3) maturity of peanuts; and 4) type of carbohydrate involved. In general, basic amino acid residues such as lysine from the protein are involved in

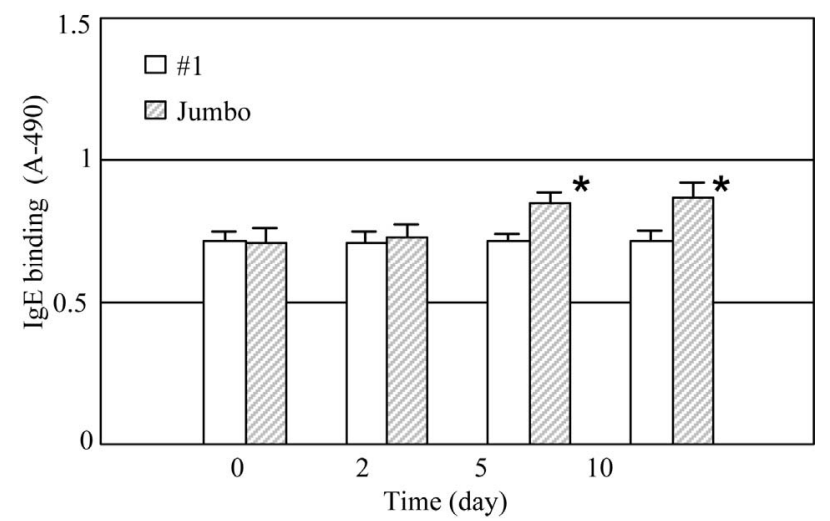

Figure 4. IgE binding of ribose-treated mature (Jumbo) and immature (\#1) raw peanut extracts in an indirect ELISA. A plate was coated with extracts treated with ribose at $50^{\circ} \mathrm{C}$ for the time indicated ( 0 - 10 days), and then incubated with a diluted pooled plasma from peanut-allergic individuals. IgE binding was detected, using a goat anti-human IgE peroxidase and a substrate of $o$-phenylenediamine dihydrochloride. Values are mean of triplicate. *Values between \#1 and Jumbo on day 5 or 10 are significantly different from each other $(p<0.05)$. the Maillard reaction, and a modification of such amino acid residues may decrease or increase IgE binding. However, in one study [13], IgE binding to recombinant peanut allergen (Ara h 2) was shown to increase even when lysine residues were not present in the allergen undergoing the Maillard reaction. The mechanism for this phenomenon was not clear. Considering the fact that peanuts can be of different composition (due to a difference in variety), harvested and cured at different locations (leading to a variation in temperature and maturity), establishment of a relationship between IgE binding and Maillard reaction may sometimes be difficult, and thereby, discrepancies may or may not exist among studies, regarding the role of Maillard reaction in peanut allergy [11-13,21].

\section{Conclusions}

Raw peanuts such as normal (Florunner) and new breed (high-oleic peanut), each sorted into mature and immature peanuts, were treated with ribose, glucose and fructose, respectively, at $37-50^{\circ} \mathrm{C}$ for $0-10$ days, and analyzed with NBT for Maillard reaction adducts (MRA). Of the sugars (ribose, glucose, and fructose) tested, only ribose produced a big difference or a unique curve pattern (i.e., the "gap" region) in MRA between mature and immature raw peanuts. High oleic peanut exhibited a similar result, indicating that it is not different from normal peanut (Florunner) in the reaction with ribose. The unique curve pattern in MRA was more pronounced at $50^{\circ} \mathrm{C}$ (day 5 and 10 ) than at $37^{\circ} \mathrm{C}$. IgE binding under this condition $\left(50^{\circ} \mathrm{C}\right.$, day $\left.5-10\right)$ increased, but only with ribose-treated mature raw peanut. It was concluded that mature and immature raw peanuts were different in MRA and $\operatorname{IgE}$ binding when treated with ribose only, and that under such a condition, mature and immature raw peanuts could be identified.

\section{Acknowledgements}

The author thanks Elena Batista and Shawndrika Reed for their technical support and Ashley Guillory for Figure drawings.

\section{REFERENCES}

[1] Y. Hellsten, L. Skadhauge and J. Bangsbo, "Effect of Ribose Supplementation on Resynthesis of Adenine Nucleotides after Intermittent Training in Humans," American Journal of Physiology-Regulatory Integrative and Comparative Physiology, Vol. 286, No. 1, 2004, pp. R182- R188. doi:10.1152/ajpregu.00286.2003

[2] M. Friedman, "Food Browning and Its Prevention. An Overview," Journal of Agricultural and Food Chemistry, Vol. 44, No. 3, 1996, pp. 631-653. doi:10.1021/jf950394r

[3] H. Jing and D. D. Kitts, "Comparison of the Antioxida- 
tive and Cytoxic Properties of Glucose-Lysine and Fructose-Lysine Maillard Reaction Products," Food Research International, Vol. 33, No. 6, 2000, pp. 509-516. doi:10.1016/S0963-9969(00)00076-4

[4] J. M. Chobert, J. C. Gaudin, M. Dalalarrondo and T. Haertle, "Impact of Maillard Type Glycation on Properties of Beta-Lactoglobulin," Biotechnology Advance, Vol. 24, No. 6, 2006, pp. 629-632. doi:10.1016/j.biotechadv.2006.07.004

[5] L. Graham, "A Comprehensive Survey of the Acid-Stable Fluorescent Cross-Links Formed by Ribose with Basic Amino Acids, and Partial Characterization of a Novel Maillard Cross-Link," Biochim Biosphysic Acta, Vol. 1297, No. 1, 1996, pp. 9-16. doi:10.1016/0167-4838(96)00082-9

[6] S. B. M. Yasir, K. H. Sutton, M. P. Newberry, N. R. Andrews and J. A. Gerrard, "The Impact of Transglutaminase on Soy Proteins and Tofu Texture," Food Chemistry, Vol. 104, No. 4, 2007, pp. 1491-1501. doi:10.1016/j.foodchem.2007.02.026

[7] S. Y. Chung, C. Butts, S. J. Maleki and E. T. Champagne, "Linking Peanut Allergenicity to the Processes of Maturation, Curing and Roasting," Journal of Agricultural and Food Chemistry, Vol. 51, No. 15, 2003, pp. 4273-4277. doi:10.1021/jf021212d

[8] T. H. Sanders, J. R. Vercellotti, P. D. Blankenship, K. L. Crippen and G. V. Civille, "Interaction of Maturity and Curing Temperature on Descriptive Flavor of Peanuts," Journal of Food Science, Vol. 54, No. 4, 1989, pp. 10661069. doi:10.1111/j.1365-2621.1989.tb07944.x

[9] T. H. Sanders, "Maturity Distribution in Commercially Sized Florunner Peanuts," Peanut Science, Vol. 16, No. 2, 1989, pp. 91-95. doi:10.3146/i0095-3679-16-2-8

[10] E. L. Williams and J. S. Drexler, "A Non-Destructive Method for Determining Peanut Pod Maturity," Peanut Science, Vol. 8, No. 2, 1981, pp. 134-141. doi:10.3146/i0095-3679-8-2-15

[11] S. Y. Chung and E. T. Champagne, "Allergenicity of Maillard Reaction Products from Peanut Proteins," Journal of Agricultural and Food Chemistry, Vol. 47, No. 12, 1999, pp. 5227-5231. doi:10.1021/jf9904416

[12] S. Y. Chung and E. T. Champagne, "Association of Endproduct Adducts with Increased IgE Binding of Roasted Peanuts," Journal of Agricultural and Food Chemistry, Vol. 49, No. 8, 2001, pp. 3911-3916. doi:10.1021/jf001186o

[13] P. Gruber, W. M. Becker and T. Hofmann, "Influence of the Maillard Reaction on the Allergenicity of rAra h 2, a Recombinant Major Allergen from Peanut (Arachis Hy- pogaea), Its Major Epitopes, and Peanut Agglutinin," Journal of Agricultural and Food Chemistry, Vol. 53, No. 6, 2005, pp. 2289-2296. doi:10.1021/jf048398w

[14] A. Ilchmann, S. Burgdorf, S. Scheurer, Z. Waibler, R. Nagai, A. Wellner, Y. Yamamoto, H. Yamamoto, T. Henle, C. Kurts, U. Kalinke, S. Vieths and M. Toda, "Glycation of a Food Allergen by the Maillard Reaction Enhances Its T-Cell Immunogenicity: Role of Macrophage Scavenger Receptor Class A Type I and II," Journal of Allergy and Clinical Immunology, Vol. 125, No. 1, 2010, pp. 175-183. doi:10.1016/j.jaci.2009.08.013

[15] S. M. M. Basha, J. P. Cherry and C. T. Young, "Free and Total Amino Acid Composition of Maturing Seed from Six Peanut (Arachis Hypogaea L.) Cultivars," Peanut Science, Vol. 7, No. 1, 1980, pp. 32-37. doi:10.3146/i0095-3679-7-1-8

[16] S. H. Ashoor and J. B. Zent, "Maillard Browning in Common Amino Acids and Sugars," Journal of Food Science, Vol. 49, No. 4, 1984, pp. 1206-1207. doi:10.1111/j.1365-2621.1984.tb10432.x

[17] S. T. Talcott, S. Passeretti, C. E. Duncan and D. W. Gorbet, "Polyphenolic Content and Sensory Properties of Normal and High Oleic Acid Peanuts," Food Chemistry, Vol. 90, No. 3, 2005, pp. 379-388. doi:10.1016/j.foodchem.2004.04.011

[18] A. Nakamura, K. Watanabe, T. Ojima, D. H. Ahn and H. Saeki, "Effect of Maillard Reaction on Allergenicity of Scallop Tropomyosin," Journal of Agricultural and Food Chemistry, Vol. 53, No. 19, 2005, pp. 7559-7564. doi:10.1021/jf0502045

[19] A. Taheri-Kafrani, J. C. Gaudin, H. Rabesona, C. Nioi, D. Agarwal, M. Drouet, J. M. Chobert, A. K. Bordbar and T. Haertle, "Effects of Heating and Glycation of $\beta$-Lactoglobulin on Its Recognition by IgE of Sera From Cow Milk Allergy Patients," Journal of Agricultural and Food Chemistry, Vol. 57, No. 11, 2009, pp. 4974-4982. doi:10.1021/jf804038t

[20] S. Nakamura, Y. Suzuki, E. Ishikawa, T. Yakushi, H. Jing, T. Miyamoto and K. Hashizume, "Reduction of in Vitro Allergenicity of Buckwheat Fag e 1 through the Maillardtype Glycosylation with Polysaccharides," Food Chemistry, Vol. 109, No. 3, 2008, pp. 538-545. doi:10.1016/j.foodchem.2007.12.075

[21] L. Mondoulet, E. Paty, M. F. Drumare, S. Ah-Leung, P. Scheinmann, R. M. Willemot, J. M. Wal and H. Bernard, "Influence of Thermal Processing on the Allergenicity of Peanut Proteins," Journal of Agricultural and Food Chemistry, Vol. 53, No. 11, 2005, pp. 4547-4553. doi:10.1021/jf050091p 